\title{
Os papéis das instituições participativas na estruturação das políticas públicas no Brasil
}

The roles of participatory institutions in structuring public policies in Brazil

\section{Introdução}

O propósito deste trabalho é qualificar o papel que as Instituições Participativas (IPs) assumiram na estruturação e na trajetória das políticas públicas brasileiras, tomando como referência os últimos trinta anos de construção democrática. Destacando a dimensão de processo da institucionalização dos setores de política, pretendemos atribuir qualidade à performance das IPs no percurso do desenvolvimento de diferentes setores de políticas.

A literatura sobre IPs acumula um legado importante de conhecimento sobre o seu papel nas políticas públicas. No entanto, os estudos abordaram essas instituições, não raramente, de maneira apartada dos processos mais amplos implicados com a estruturação das políticas públicas, ou seja, com a criação e incremento de suas respectivas capacidades estatais, entendidas, grosso modo, como as condições das quais dispõe o Estado para planejar e implementar as políticas. Assim, consideramos que ainda foi pouco explorada a qualidade da atuação das IPs, bem como o seu diferencial, para

\footnotetext{
1 Professora da Universidade Estadual de Maringá e pesquisadora do Nuppol/UEM, Maringá - PR, Brasil. E-mail: <carlaalm@uol.com.br>

2 Professora do Departamento de Ciências Sociais e coordenadora do Grupo de Estudos e Pesquisa Participação e Democracia (GEPPADE) da Universidade Estadual Paulista (Unesp/Araraquara), Araraquara, São Paulo, Brasil. E-mail: <carla.martelli@unesp.br>

3 Doutor em Ciência Política. Universidade Estadual de Campinas (Unicamp/Campinas), Campinas, SP, Brasil.E-mail: <coelhorgs@yahoo.com.br>
} 
a compreensão do lugar que ocuparam e/ou ocupam em distintos momentos da trajetória dos setores de políticas. Por exemplo, as IPs assumiram papel protagonista, coadjuvante, ou estavam ausentes na gênese do processo de institucionalização da política? Elas mantêm papel codeterminantes no desenvolvimento e nos projetos reformadores do setor, ou o papel é contingencial e episódico?

Assumimos aqui que enfrentar essas perguntas ajuda a elucidar competências desempenhadas pelas IPs nas diferentes políticas, que ficam encobertas se seguidos apenas os critérios geralmente empregados para classificar suas experiências bem-sucedidas de institucionalização. Tais critérios, frequentemente, tomam como referência de avaliação o percurso completo de institucionalização, o que implica considerar aquelas IPs que se difundiram uniformemente pelo território nacional, com desenhos institucionais uniformes, de caráter deliberativo e decisões de efeito vinculantes, como são os casos típicos da Saúde e Assistência Social. Os conselhos dessas áreas passaram da fase da "inovação", venceram a da "difusão" e alcançaram a da "legitimidade" e "estabilidade" (LAWRENCE; WINN; JENNINGS, 2001). Nesses casos, as IPs receberiam, portanto, o "selo" de instituições fortes, desempenhando papéis codeterminantes no desenvolvimento de suas respectivas políticas e, presumidamente, com condições de maior resiliência em contextos desfavoráveis.

Gurza Lavalle e Barone (2015) mostram que, de fato, os conselhos de Saúde e, podemos dizer também, o da Assistência, integram o grupo mais seleto daqueles que, sob o efeito de indução federal, expandiram-se uniformemente pelo território nacional, tendendo à universalização. Mas os autores reconhecem que a maior parte dos conselhos existentes no país compõe os grupos daqueles que se disseminaram desigualmente, alcançando média ou baixa expansão, como, entre outros, os conselhos do Meio Ambiente, Habitação, Idoso, Direitos Humanos, Juventude, Direitos da Pessoa com Deficiência, LGBT, Direitos da Mulher, Promoção da Igualdade Racial. Nesse sentido, tais conselhos assumiram uma variação 
maior ao longo do tempo no que diz respeito à expansão e ao grau de institucionalização.

Esses últimos grupos de conselhos tenderiam a ser também menos resilientes no contexto político desfavorável que as IPs enfrentam no Brasil pós-eleições presidenciais de 2018, com a vitória das forças conservadoras ${ }^{4}$. Segundo Almeida (2020, p. 19), o Conselho Nacional de Saúde seria o caso típico de resiliência, por ter preservado seus objetivos e funções, ao mesmo tempo em que tem adaptado-se às adversidades do momento, mobilizando a participação de atores sociais de modo a incidir na política. Classificado na outra ponta, estaria o Conselho Nacional de Direitos da Mulher, que expressaria o "ocaso da participação institucional" em termos de sua fragilização diante do atual contexto, em que o seu poder e valor perdem importância para as políticas de gênero.

Para o nosso propósito, interessa qualificar o papel que as IPs alcançaram na trajetória de seus setores, sejam elas muito ou pouco resilientes em contextos adversos. Não se trata de diminuir a importância de se avaliar o desempenho das IPs neste momento de inflexão política. Ao contrário, sugerimos que até mesmo essa avaliação pode beneficiar-se dos achados de um olhar que capte a variação dos seus papéis no percurso de institucionalização das políticas públicas. Dada a histórica baixa permeabilidade do Estado brasileiro à circulação de elites, a construção e a ocupação de IPs tornaram-se, a partir do processo de redemocratização do país, repertórios de ação importantes para atores interessados em projetos reformadores das políticas, ou na criação de novas políticas públicas orientadas à ampliação do acesso a direitos. Assim, a proposta deste trabalho é explorar o que nos parece ainda estar na sombra: a despeito de não terem cumprido o "percurso modelo" de institucionalização e, portanto, de não contarem com os atributos de "instituições fortes", algumas IPs desempenharam papel fundamental para a história de

4 No início de seu mandato, o presidente da República publicou o Decreto n. 9.759/2019, que extinguiu e/ou limitou a atuação de uma série de instâncias participativas. O decreto foi um evidente sinal de que as IPs enfrentariam dificuldades no novo governo, o que já tinha ficado certo com a revogação do Conselho Nacional de Segurança Alimentar (MP n. 870), no primeiro dia da nova gestão. 
determinadas políticas públicas, configurando-se como vértebras da própria construção do sistema público de garantia de direitos no país. Acrescentar essa perspectiva ao já rico campo de estudos sobre IPs no Brasil pode valorizar o seu legado, também, no campo de estudos de políticas públicas.

Para desenvolver esses argumentos e enfrentar as perguntas que anunciamos nesta introdução, o artigo está organizado em mais três seções. Na primeira, mobilizamos a bibliografia que tem se dedicado a trabalhar com o tema da institucionalização da participação, destacando-se os ganhos de uma abordagem que enfatiza a mútua constituição entre capacidades estatais nas suas dimensões político-relacionais e técnico-administrativas. Na segunda seção, mostramos a importância de se qualificar a performance das IPs para a compreensão do papel que exercem ou exerceram em seis setores de políticas públicas, intencionalmente selecionadas de acordo com os nossos propósitos, após a avalição qualitativa: Mulheres; Segurança Alimentar; Cultura; Meio Ambiente; Saúde; e Assistência Social. Nosso argumento é o de que podemos, a partir dessas políticas, sugerir uma tipologia para qualificar os papéis exercidos pelas IPs nas políticas públicas: reformador, fundante ou episódico/contigencial. A última seção juntará às analises algumas considerações finais. Nela, sugerimos que a variação dos papéis exercidos pelas IPs nas políticas públicas pode ser explicada pela forma como interagiram, de maneira específica e própria em cada área, três fatores: (i) oportunidades políticas; (ii) dinamismo e configuração das comunidades de políticas; (iii) capacidades estatais técnico-administrativas pré-existentes nas políticas.

\section{Abordagens sobre a institucionalização da participação}

Desde os anos 2000, o debate acerca da participação social no Brasil, em grande medida, traduziu-se em discussões sobre Instituições Participativas. Não sem razão, Gurza Lavalle, Voigt e Serafim (2016, p. 610) assinalaram, diante do que prevalecia nas décadas anteriores, que "a literatura deslocou os termos do debate ao promover uma nova agenda de pesquisa não mais sobre 
participação, mas sim, emblematicamente, sobre instituições participativas (IPs) e sua efetividade".

Embora o termo Instituições Participativas não seja consensual e ainda não tenha recebido tratamento conceitual suficiente nos estudos da participação (BARBOSA; KERBAUY, 2015; BORBA, 2011), mostra-se bastante útil, pois não apenas serviu como denominação comum para a variedade de instâncias participativas criadas no país no pós-CF/1988, mas permitiu, sobretudo, uma mudança qualitativa na sua abordagem. O termo exigiu um maior rigor na especificação e na análise de um tipo particular de participação, aquela que acontece no interior de instituições. Uma delimitação mais específica foi oferecida por Côrtes (2011, p. 137), que entende as IPs "como mecanismos de participação criados por lei [...] que permitem o envolvimento regular e continuado de cidadãos com a administração pública, tanto diretamente quanto através de representantes". Nas suas palavras, "são instituições porque não se constituem em experiências episódicas ou eventuais de participação em projetos ou programas governamentais [...]. Ao contrário, estão instituídas como elementos característicos da gestão pública brasileira" (Ibidem, p. 137).

Decerto, a amplitude e extensão das experiências sob a designação "Instituição Participativa" levou a literatura a cunhar o correlato termo "arquitetura da participação" (TEIXEIRA; SOUZA; LIMA, 2012; ISUNZA VERA; GURZA LAVALLE, 2012), que inclui: conselhos, conferências, orçamentos participativos, audiências públicas, entre outros, nas distintas esferas de governo - federal, estadual ou municipal. Dada tal arquitetura participativa, ou, considerado o grau de institucionalização e capilaridade territorial dos arranjos participativos, nos termos de Gurza Lavalle (2011, p. 13), houve um ponto no pós-CF/1988, no auge (pode-se dizer), em que o "processo histórico [...] transformou a participação em uma feição institucional do Estado no Brasil".

Gurza Lavalle e colaboradores $(2019$, p. 22) observam que institucionalização implica a transformação de algo em instituição, pressupondo processo, devir, ou seja, tem a dizer sobre sucessão 
de momentos, trajeto, transcurso. Tal como proposto, a ideia de institucionalização nos remete aos processos implicados com a transformação de valores, interesses e demandas de atores sociais em instituições. Na linhagem institucionalista, as instituições são definidas, de forma geral, como as regras do jogo (HALL; TAYLOR, 2003). Porém, entendida a institucionalização como um processo, estão em jogo mais precisamente as definições dessas regras. Essa abordagem permitiu enfatizar o jogo das interações socioestatais que constroem e conformam as instituições, lente que nos parece especialmente adequada para a compreensão da constituição de políticas públicas. Como sugerem Gurza Lavalle e colaboradores (2019, p. 66):

Desde a concepção duma política pública, da sua formulação às suas execução e avaliação, o complexo dos instrumentos e modos pelos quais o Estado faz o que faz e como o faz está [...] nas interações com organizações da sociedade civil e movimentos sociais, enfim, nas interações socioestatais.

Essas interações produziriam "encaixes", conceito desenvolvido pelos estudos neoinstitucionalistas para designar as cristalizações institucionais que expressam os acessos de atores sociais ao Estado. Refinando o conceito a partir do caso brasileiro, Gurza Lavalle e colaboradores (2019) argumentam que os encaixes podem variar horizontal e verticalmente, e também em termos do seu grau de articulação. Conselhos e conferências, por exemplo, podem operar expressando distintos "encaixes": "horizontais", se no mesmo nível federativo; ou "verticais", quando agem como vetores de uma conexão dentro de uma área de política pública nos distintos níveis federativos. Encaixes verticais e horizontais variam em termos de sua articulação, possuindo, assim, diferentes potenciais de alcance nas políticas públicas. Para além de IPs, os encaixes assumem formatos distintos, como Planos, normativas, órgãos, entre outros. Portanto, é possível ver os encaixes como aquelas capacidades estatais que resultam das interações socioestatais, expressando, desse modo, a 
sedimentação, no Estado, de demandas de atores coletivos. Para os autores, o desafio empírico é, então, identificar quando capacidades estatais resultam de encaixes.

De uma perspectiva ampla, capacidade estatal pode ser entendida como a habilidade do Estado em implantar decisões e conseguir alcançar fins almejados (PIRES; GOMIDE, 2016; GOMIDE; PEREIRA; MACHADO, 2017). Gomide, Pereira e Machado (2017) estabelecem duas dimensões do conceito: a técnico-administrativa, que se refere aos recursos burocráticos, organizacionais, financeiros e tecnológicos existentes; e a político-relacional, que corresponde às habilidades e procedimentos de inclusão de múltiplos atores visando à construção de consensos, articulações e coalizões de suporte às políticas. Souza (2017) resgata uma dimensão importante do conceito ao enfatizar sua não fixidez, ou seja, capacidades estatais dizem respeito às condições necessárias à ação estatal, embora estas não sejam seus atributos, estando disponíveis em certos momentos, e em outros, não.

Neste trabalho, julgamos que os estudos brasileiros sobre as IPs, ainda que tenham avançado significativamente ao colocar em foco os processos de institucionalização, não retiraram desdobramentos analíticos suficientes de uma abordagem relacional, que permita compreender a mútua constituição entre aquelas instituições e as demais capacidades técnico-administrativas no processo de estruturação de políticas públicas no Brasil. Por exemplo, o estudo de Mayka (2019) mostra como os conselhos e as conferências de Assistência Social e Saúde tornaram-se centrais no processo de implementação do projeto reformador nessas áreas, elaborado e implementado ao longo das décadas de 1980 e 1990. Essa centralidade resultou, embora não linearmente, da agência contínua de atores em um contexto favorável às lutas por direitos, processo que legou força institucional às IPs dessas áreas. Como a autora designa, IPs fortes são aquelas cujo desenho institucional lhes confere autoridade e incidência efetiva na política pública, sendo valorizadas por atores sociais e estatais como lócus de representação de interesses e com 
abrangência e uniformidade formal no território ${ }^{5}$. Desse modo, na mesma medida em que democratizaram os processos decisórios das políticas de Saúde e Assistência Social, aspecto enfatizado nos estudos sobre IPs, os conselhos e as conferências foram também cruciais na construção e implementação do projeto reformador que criou e implementou o Sistema Único de Saúde (SUS) e o Sistema Único de Assistência Social (SUAS) ${ }^{6}$.

Contudo, como já pontuado, o foco de Mayka em IPs fortes apresenta limites para enxergamos a variedade de papéis assumidos por essas instâncias na estruturação das políticas brasileiras. Esse foco dá conta de explicar um conjunto específico de IPs, cujo processo de institucionalização cumpriu o percurso completo. Nossa proposta é, em contraste, captar os diferentes papéis que as IPs cumpriram, em face de distintos níveis e momentos de sua institucionalização, na trajetória das diferentes áreas de políticas públicas. Os conselhos, por exemplo, multiplicaram-se por um conjunto muito variado de políticas que estavam ainda pouco estruturadas no país.

Consideramos que o trabalho de Martelli, Tonella e Coelho (2021) oferece-nos um ponto de partida bastante profícuo nessa direção. Os autores apresentam uma abordagem relacional para a compreensão da estrutura institucional e da arquitetura participativa presente em diferentes áreas de políticas públicas, a partir da construção de dois índices. O IEI (Índice de Estrutura Institucional) é composto pelo ano de criação e existência de ministérios, secretarias nacionais, estaduais, municipais, de sistemas nacionais, de planos e fundos. Está relacionado à dimensão "técnico-administrativa" das capacidades estatais, à qual são acrescentados dois aspectos: antiguidade e capilaridade. $\mathrm{O}$ outro índice, $\mathrm{O}$ IAP (Índice de Arquitetura Participativa), diz respeito ao grau de

\footnotetext{
5 Para Mayka (2019), esses atributos não resultam do ato de criação de uma instituição, mas de um processo em que a experimentação funciona como um farol a indicar quais mudanças no desenho institucional são necessárias para que seus objetivos sejam cumpridos.

6 Para a autora, as IPs apresentam maiores chances de se tornarem fortes quando integram projetos reformadores setoriais mais amplos, em que são abertas janelas de oportunidades para que novos atores passem a enxergar tais instituições como estratégias para a defesa de seus interesses em contextos de mudanças e incertezas.
} 
institucionalização da participação, este relacionado à dimensão político-relacional das capacidades estatais. Foi mensurado pela existência de conselhos e conferências nos três níveis da federação e pela idade de cada IP, a fim de perceber sua antiguidade no setor ${ }^{7}$.

Embora comportem variáveis restritas quando levamos em conta a complexidade dos processos envolvidos com a institucionalização, esses índices são inéditos na bibliografia por, pelo menos, três razões: (i) pela amplitude territorial e setorial, (ii) por possibilitar análises de conselhos e conferências em conjunto; e, sobretudo, (iii) por permitir uma análise relacional entre variáveis da participação e variáveis de outras capacidades estatais envolvidas nas políticas públicas. Desse ponto de vista, sugerem pistas para avançarmos no conhecimento da variação do papel exercido pelas IPs na trajetória das políticas públicas.

Um olhar desagregado nos indicadores que compõem os índices nos mostra que, em várias políticas, incrementos nas capacidades técnico-administrativas foram antecedidos ou simultâneos à criação de conselhos nacionais ou realização de conferências nacionais. A título de exemplos, a criação do SUS (1988) foi antecedida da $8^{\text {a }}$ Conferencia da Saúde (1986); a instituição do Fundo da Assistência Social (1993) ocorreu no mesmo ano da criação do Conselho (1993); a $1^{\text {a }}$ Conferência Nacional da Educação (1988) foi seguida do Plano Nacional (1996); e a $1^{\text {a }}$ Conferência Nacional da Cultura (2006) precedeu a criação do Plano e do Sistema Nacional da área (2012). São informações que sugerem uma associação positiva entre incrementos na dimensão político-relacional, aqui identificados com as IPs, e o fortalecimento da dimensão técnico-administrativa dessas políticas públicas.

Ainda que essa associação positiva tenha de ser mais bem verificada e explorada, o que será feito na próxima seção para as seis áreas de políticas, trazemos o gráfico abaixo por permitir um olhar integrado da arquitetura participativa e da estrutura institucional

7 As fontes principais para a construção dos índices foram as Munics e as Estadics dos anos de 2013 e 2014. Para uma discussão metodológica de dados e gráfico, que serão apresentados adiante, ver o trabalho citado (MARTELLI; TONELLA; COELHO, 2021). 
de cada política ali considerada, construído a partir da distribuição dos índices em quadrantes de acordo com a performance das suas médias. Vejamos:

Gráfico 1 - Arquitetura da participação e estrutura institucional

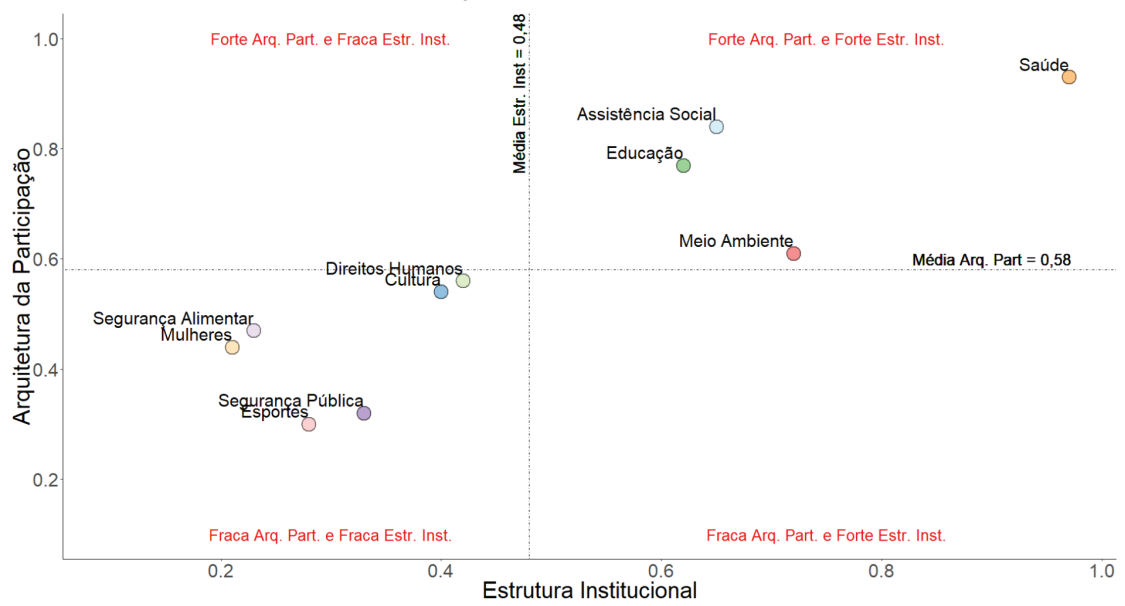

Fonte: Martelli, Tonella e Coelho (2021).

Observe-se que uma forte arquitetura participativa está associada a uma expressiva estrutura institucional; assim, também, uma fraca arquitetura participativa está ligada a uma insuficiente estrutura institucional. Então, não apenas os incrementos nas capacidades político-relacionais e técnico-administrativas das políticas públicas tenderam a ocorrer próximos no tempo, mas, também, as duas dimensões adquiriram o mesmo grau de robustez nas diferentes áreas. Assim, parece-nos que o sistema das políticas públicas no Brasil está profundamente marcado pelas relações constitutivas entre IPs e capacidades técnica-administrativas. O IAP e o IEI instigaram-nos a explorar a maneira como, em cada área de política, essa relação aconteceu. 


\section{Qualificando o papel das IPs em seis setores de políticas}

Para qualificar o papel das IPs na estruturação do sistema de direitos, selecionamos seis áreas de políticas públicas para um olhar mais detalhado. O nosso argumento é o de que podemos, a partir da análise da trajetória dessas políticas, sugerir uma tipologia para os papéis exercidos pelas IPs na institucionalização de seus respectivos setores, quais sejam: papel reformador, fundante ou episódico/ contingencial.

\section{As áreas de Saúde e Assistência Social: papel reformador}

No Gráfico 1, as áreas de Saúde e de Assistência Social possuem forte arquitetura participativa e forte estrutura institucional. Para além de ocuparem a mesma região no gráfico, as duas áreas são tratadas em conjunto porque as suas respectivas IPs tiveram um papel crucial para uma reforma profunda dos objetivos e estruturação das capacidades então existentes nos respectivos setores, razão pela qual assumem o papel de instituições participativas reformadoras das políticas, tal como identificou, ainda, a análise de Mayka (2019).

Na Saúde, a década de 1970 assume destaque porque marca um período importante de pluralização e fortalecimento da comunidade de política do setor. O grande protagonista foi o Movimento Sanitarista, que, na esteira da luta pelo restabelecimento da democracia, reivindicava um projeto de seguridade social moldado nos princípios do Estado de bem-estar europeu. O movimento surgiu a partir de uma concepção teórica sobre a saúde coletiva, construída e desenvolvida no âmbito acadêmico, mas que ganhou espaço na burocracia pública. Articulou, portanto, um conjunto diversificado de atores da sociedade civil e do Estado em torno de uma proposta de reforma - redes de profissionais da saúde, estudantes, acadêmicos, trabalhadores da saúde pública, diversas associações, sindicatos e movimentos populares -, e o fez não "fora das instituições", mas "via instituições". Essa articulação transformou a Conferência Nacional de Saúde em uma ampla mobilização da sociedade civil em prol da reforma sanitária (DOWBOR, 2012). 
Lembramos que a primeira Conferência de Saúde aconteceu em 1941, antes mesmo da criação do Ministério da Saúde (1953) ${ }^{8}$. Também o Conselho Nacional de Saúde (CNS) foi criado em 1937, mas é somente a partir da ação do movimento sanitarista, na $8^{\text {a }}$ Conferência de 1986, e com a conquista das reformas constitucionais, que o CNS passa a ser deliberativo e organizado de forma escalonada, nos munícipios e estados, com representantes eleitos pela comunidade entre usuários, prestadores de serviço e vários segmentos sociais. Ou seja, a comunidade de política, fortalecida e pluralizada pela ação do movimento sanitarista, em um contexto favorável à luta por direitos e, portanto, de oportunidades políticas" passa a ocupar conselhos e conferências, valorizando-os como instâncias de representação de interesses de vários segmentos com poder de interferir na agenda governamental.

Foi assim que a $8^{\text {a }}$ Conferência reuniu subsídios para a reformulação do Sistema Nacional de Saúde, fundamentado no direito público e universal à saúde, além de amparado por mecanismos de controle exercido pela sociedade, tal como instituído pela Constituição de 1988. Assim, um conjunto de atores, sob oportunidades políticas abertas, conseguiu alterar a correlação de forças então presentes na área da Saúde, pluralizando e mobilizando a sua comunidade de políticas públicas em nome de um projeto reformador para o setor, que obteve reconhecimento institucional na $8^{\text {a }}$ Conferência e que foi, posteriormente, implementado via CNS. $\mathrm{O}$ resultado foi a grande reforma sanitária que institucionalizou o SUS, o maior sistema público de saúde universal que atende a uma população de mais de 200 milhões de habitantes.

A década de 1990 marca outro período fundamental, pois registra ganhos importantes do ponto de vista técnico-administrativo com a construção do arcabouço institucional e decisório do SUS, respeitando a organização federativa; a descentralização e o

8 Antes de possuir pasta própria, a Saúde estava organizada junto à área de Educação - Ministério dos Negócios da Educação e Saúde Pública (1930) e Ministério da Educação e Saúde (1937).

9 Utilizamos a ideia de oportunidades políticas definida por Tarrow (2009): trata-se das condições ou fatores presentes no ambiente político, mais contextuais ou persistentes, que fornecem incentivos à ação coletiva ao afetarem as expectativas de atores quanto ao sucesso ou fracasso de suas inciativas. 
fortalecimento dos sistemas municipais de saúde; a expansão das ações e serviços no território nacional; a reorganização do modelo de atenção com ênfase na atenção primária; e a definição de novas e estáveis fontes de financiamento (MENICUCCI, 2019). Os ganhos político-relacionais vêm, especialmente, com a Lei n. 8.080/1990, que estabeleceu a participação da comunidade como um princípio do SUS e atribuiu aos conselhos a faculdade de fiscalizar os recursos financeiros do setor. Além disso, foi criada a Lei n. 8.142/1990, que dispôs sobre a participação definindo os conselhos como instância colegiada do sistema de saúde, condicionando as transferências de recursos setoriais à sua existência. As prerrogativas legais induziram a criação de conselhos municipais e estaduais por todo o território nacional, uma vez que, para receber recursos financeiros federais, as secretarias de saúde, estaduais e municipais deveriam ter: fundo de saúde, conselho de saúde, plano de saúde, relatório de gestão, considerável contrapartida de recursos financeiros oriundos dos orçamentos próprios destinados à função saúde, plano de carreira, cargos e salários (CÔRTES, 2002).

Tal como a Saúde, a área de Assistência Social segue o padrão de universalização, com conselhos municipais e estaduais espalhados por todo o território nacional (GURZA LAVALLE; BARONE, 2015). Mas a estruturação do setor é mais tardia e intermitente, quando comparada com a Saúde, pois, até fins dos anos 1980, a Assistência Social não se constituía como uma área de política devidamente reconhecida e estruturada no Estado. No período varguista, ainda que o Conselho Nacional do Serviço Social (1938) e a Legião Brasileira de Assistência (1942) tenham sido criados para conferir maior organicidade às ações públicas voltada ao atendimento à população vulnerável, essas ações permaneceram sob forte controle de execução de entidades assistenciais, predominantemente de natureza religiosa, que implementavam os seus serviços por meio de repasses estatais na forma de convênios. Essas ações não eram normatizadas em termos de conteúdo, e os controles sobre elas eram frágeis, dispersos e fragmentados. Então, mesmo 
que possamos encontrar um lastro de engajamento estatal na área, ele é muito frágil se comparado com a Saúde.

A Constituição de 1988 foi o marco legal para a política, quando dispõe de seção específica para a área (art. 203, CF/1988) inscrevendo a Assistência Social como um direito a ser garantido pelo Estado. A política ganha ossatura técnico-administrativa com a Lei Orgânica da Assistência Social (LOAS) em 1993, na qual foram instituídas medidas administrativas de âmbito federal, como fundos nacional, estaduais e municipais; mecanismos de transferência de recursos financeiros da esfera federal para a estadual e municipal; comissões intergestoras de coordenação federativa; municípios como os principais responsáveis pela implementação das políticas nos territórios sob sua jurisdição. Do ponto de vista político-relacional, o setor se fortalece com a institucionalização de fóruns participativos - conselhos e conferências - nos níveis federal, estadual e municipal. A partir da LOAS, o Conselho Nacional de Assistência Social (CNAS) assume protagonismo em todo o processo posterior de institucionalização do setor, deixando de ser um órgão que apenas certificava entidades como beneficentes de Assistência Social, garantindo-lhes isenções fiscais, como fazia o seu antecessor, o Conselho Nacional de Serviço Social, criado em 1938 (CÔRTES, 2015).

Tal como na Saúde, o contexto da redemocratização foi importante para a renovação e a organização de profissionais atuantes na área. Por exemplo, em 1979, acontece o "Congresso da Virada", que sinalizaria a nova configuração adquirida pelos profissionais atuantes no setor (FREITAS et al., 2018). Articulados na América Latina com o "Movimento de Reconceituação do Serviço Social", esses profissionais passaram a disputar e, ao mesmo tempo, adensar e pluralizar a comunidade de política do setor. Esses profissionais participaram e tiveram papel importante na $8^{\text {a }}$ Conferência Nacional de Saúde e, afinados com os princípios do SUS, levam para a Assistência Social o modelo então implementado naquela área, fortemente marcado pela articulação entre "participação" e "política pública", de cobertura universal, não contributiva e baseada na ideia de direitos. 
Diferentemente da área da Saúde, a Assistência não contava ainda de forma suficiente com apoiadores localizados na burocracia estatal comprometidos com o projeto reformador, capazes de lhe dar sustentação em contexto desfavorável, até porque as suas capacidades estatais eram mais frágeis do que as existentes na Saúde. De todo o modo, a criação do conselho nacional representou um espaço permanente para a articulação da rede de atores comprometida com o projeto reformador. Isso foi fundamental para que, nos anos 2000, sob uma nova oportunidade política - a eleição do presidente Lula, que resultou na inclusão de novos burocratas na máquina do Estado agora comprometidos com a LOAS -, o CNA e as Conferências pudessem dar continuidade à implementação do projeto reformador da área.

O ponto culminante do processo foi a criação de ministério próprio, o Ministério do Desenvolvimento Social e Combate à Fome (MDS) e do Sistema Único de Assistência Social (SUAS), em 2004. Note-se que, nesse processo, o CNAS contou com o apoio da burocracia estatal, sendo reconhecido como centro irradiador, ao lado conferências, da normatização que organizava o sistema em formação, ocupando o topo de uma cadeia de fóruns participativos estaduais e municipais, capaz de levar as decisões aos estados e municípios. Não por outra razão, no setor de Assistência Social, como no de Saúde, os conselhos tiveram um papel reformador, com importância crucial para a consolidação do SUAS. Os consensos construídos no interior do CNAS estavam assentados em indivíduos, grupos e organizações que, independentemente de estarem nos governos, em associações profissionais, sindicatos ou mesmos em organizações prestadoras de serviços, compartilhavam a noção de que a assistência social era um direito dos cidadãos. Ainda que as concepções filantrópicas predominantes até então não tenham deixado de estar presentes, prevaleceu, nesse período, nas decisões mais impactantes, esse consenso.

A consolidação dos marcos legais ocorreu nas conferências realizadas nesse período, como a Norma Operacional Básica da Assistência Social (NOB/SUAS) de 2012, que reforçou as diretrizes 
anteriores na direção do planejamento e pactuação de metas e de resultados. A estrutura técnica-administrativa mostra um setor bastante consolidado por todo o território nacional. O balanço atual é que todos os estados contam com Secretarias de Assistência Social (ou equivalente) e $80 \%$ dos municípios dispõem de secretarias exclusivas, 8240 Centros de Referência da Assistência Social (CRAS) e 2521 Centros Especializados da Assistência Social (CREAS), conforme indica o Censo Suas (2016). Importante notar que o setor passou por mudanças importantes em 2019, como a extinção do Ministério Social e Combate à Fome (Lei n. 13.844/2019), substituído pelo Ministério de Desenvolvimento Social e Agrário; e a extinção da Secretaria Especial de Desenvolvimento Social, que foi incorporada ao Ministério da Cidadania, juntamente com Esporte e Cultura.

Podemos dizer que tanto no caso da Saúde como na Assistência Social, os conselhos e as conferências assumiram protagonismo nas suas grandes reformas e o fizeram seguindo sendo codeterminantes no desenvolvimento de sistemas, fundos próprios, ministérios e planos. Resta observar, nas próximas pesquisas, como responderão às mudanças em curso, decorrentes das inflexões no contexto político.

\section{Políticas para Mulheres e Segurança Alimentar: papel fundante}

Conforme o Gráfico 1, as Políticas para Mulheres e de Segurança Alimentar ocupam o quadrante que designa fraca arquitetura participativa e insuficiente estrutura institucional. Além de compartilharem essa posição, tratamos as duas áreas em conjunto por apresentarem um padrão semelhante no que diz respeito ao papel das IPs no ritmo e na dinâmica de sua institucionalização. Um ponto crucial para a compreensão desse padrão é a ausência, ou precária presença de uma estrutura institucional - ministérios, secretarias, planos, fundos, entre outros - previamente à criação de conselhos e realização de conferências nacionais, o que também explica as suas posições no gráfico. Nas duas áreas, a criação de capacidades estatais técnico-administrativas mais especializadas e a própria 
configuração e fortalecimento de suas respectivas comunidades de políticas públicas se fizeram em paralelo à criação de suas IPs. Mediante oportunidades políticas e a incidência de um conjunto de atores nesses contextos favoráveis, as IPs constituíram-se em importantes portas de entrada para demandas associadas à criação de estruturas institucionais de políticas públicas ainda nascentes, bem como contribuíram para articular as redes de ativismo vinculadas aos seus campos de atuação, colaborando na conformação das respectivas comunidades de políticas.

No caso das políticas para mulheres, o marco desse processo foi a criação do Conselho Estadual da Condição Feminina (CECF/SP), em 1983, e do Conselho Nacional dos Direitos da Mulher (CNDM), em 1985. Como analisaram Schumaher e Vargas (1993, p. 353), "no sendeiro aberto em São Paulo [...], abrem-se no país novas vertentes para a discussão da 'institucionalização do feminismo"'. Esses conselhos intervieram nos conteúdos e ajudaram a acumular as condições para disseminação e implementação de programas e iniciativas que, naquele momento, inauguravam a criação de programas estatais mais especificadamente voltados às mulheres, como o Programa de Assistência Integral à Saúde da Mulher (1986) e a primeira Delegacia Especializada na Defesa da Mulher (1985), em São Paulo (COSTA, 2009; SCHUMAHER; VARGAS, 1993).

Schumaher e Vargas (1993) assinalam que o CNDM passou a ser consultado por secretários estaduais e municipais sobre "como fazer políticas para mulheres", fornecendo subsídios para os subníveis federativos para a estruturação de políticas. O CECF/SP e o CNDM funcionaram como "nós" de uma rede de ativismo feminista e de movimento de mulheres e ajudaram a disponibilizar a expertise que estava na sociedade civil para o engajamento estatal numa área de política então nascente, que não contava com estruturas previamente estabelecidas. Por isso, ainda que essas instâncias tenham minguado no período seguinte, algumas análises ressaltam o papel fundamental que tiveram para que o Estado passasse a agir no terreno das políticas públicas específicas para mulheres: 
Até a constituição do CNDM, o Estado não possuía política pública específica para a mulher, salvo alguns programas na área da saúde. A política levada a cabo pelo conselho provocou, portanto, alterações no cenário nacional. Se foram grandes ou pequenas, permanentes ou não, ainda é difícil avaliar. De toda maneira, fazem parte do processo histórico. (SCHUMAHER; VARGAS, 1993, p. 358).

A criação do CNDM e do CECF/SP está associada a dois fatores conjunturais favoráveis. De um lado, o avanço das forças partidárias de oposição ao regime militar favoreceu a incorporação, em propostas de governo, de bandeiras oriundas dos movimentos sociais. De outro, as Conferências Mundiais da Mulher organizadas pela ONU no período (1975 e 1980) exerceram pressão sobre os governos nacionais para a criação de políticas promotoras dos direitos das mulheres. Essas oportunidades foram aproveitadas pelos movimentos feministas e de mulheres no Brasil que, desde a década de 1970, adquiriram relevância no contexto mais amplo das lutas contra o regime militar, acumulando importantes recursos em termos de organização e mobilização, com a estruturação de fóruns de debates internos.

A criação dos conselhos mencionados foi, então, resultado da agência de vertentes feministas, que, apropriando-se da oportunidade aberta pelo clima de oposição ao regime e pelo fortalecimento, no âmbito internacional, da pauta das mulheres, apostaram na institucionalização de demandas junto ao Estado. Na esteira de criação do conselho de São Paulo e do CNDM, outros conselhos estaduais e municipais surgem no período, como em Salvador (1986), Teresina (1986), Natal (1986), Goiânia (1985) e Belém (1986). Desse modo, como ressaltou Bezerra (2014), o processo de criação de Conselhos de Direitos da Mulher ocorreu antes mesmo da primeira eleição presidencial direta e, acrescentamos, da promulgação da Constituição de 1988. Os conselhos, e particularmente o CNDM e o CECF/ SP, colaboraram de maneira importante para o desencadeamento do processo de reconhecimento de que os direitos das mulheres 
deveriam ser alvo da proteção estatal; da transformação das redes do ativismo feminista em uma comunidade de política mais coesa e atuante; e para a conformação e a disseminação, mesmo de modo fragmentado, de programas voltados às mulheres no Estado.

Em comparação ao caso das mulheres, programas voltados à assistência alimentar para populações vulneráveis têm um lastro maior no Estado, que remonta ao governo varguista. Sob influência dos estudos de Josué de Castro sobre fome e nutrição no Brasil, e de sua ação junto à burocracia estatal, entre as décadas de 1930 e 1970, vários programas e órgãos governamentais especializados foram criados, ainda que posteriormente alterados ou descontinuados, para prover alimentação a determinados grupos populacionais ${ }^{10}$. A insuficiência de recursos, a descontinuidade e a falta de articulação intragovernamental parecem ter sido a marca das estruturas e dos programas então criados, o que comprometeu a constituição de um sistema de política propriamente dito nessa área (SILVA, 2014).

O tema ganharia fôlego, sob um enquadramento inédito, na década de 1980, no processo de redemocratização quando movimentos organizados em torno da alimentação e nutrição ganham força e o conceito de Segurança Alimentar é introduzido no debate público, reivindicando a alimentação como direito de todo cidadão e dever do Estado $^{11}$. A mobilização em torno dessa bandeira ganhou expressão na $8^{\text {a }}$ Conferência Nacional de Saúde (1986), o que levou à convocação da I Conferência Nacional de Alimentação e Nutrição (1987) e à proposta de criação de um sistema de segurança alimentar, com a presença de conselho. Entretanto, a rede ativista da Segurança Alimentar logrou menos sucesso naquele momento, se comparada a

10 São exemplos a criação do Serviço Central de Alimentação (1939) e a constituição da Comissão Nacional de Alimentação (1945), responsável pela elaboração do I Plano Nacional de Alimentação e Nutrição (Pronan). Na década de 1960, Silva (2014) nota também a criação de estruturas institucionais que tiveram papel importante na promoção de políticas voltadas à produção, armazenagem e abastecimento de alimentos pelo governo federal, como a Companhia Brasileira de Alimentos e a Companhia Brasileira de Armazenamento. Na década de 1970, o Programa Nacional de Alimentação e Nutrição e a elaboração do II Pronan marcaram o avanço da ação governamental nessa área (SILVA, 2014).

11 Como informam Moura e Nicoletti (2016), o conceito remonta a uma proposta de política de abastecimento surgida em 1986, que tinha inspirações na concepção de segurança alimentar da FAO (Organização das Nações Unidas para a Alimentação e a Agricultura). 
da Assistência Social, em garantir na Constituição de 1988 o respaldo institucional que possibilitasse desencadear um processo amplo de reforma setorial ${ }^{12}$. Sob um contexto desfavorável à ampliação de políticas orientadas a garantir direitos, no governo Collor de Mello os programas e estruturas ligados ao tema foram desativados. As demandas pela institucionalização de uma política de segurança alimentar ganhariam novo fôlego no marco da nova oportunidade política aberta pelo impeachment de Collor, com a criação do Consea (Conselho Nacional de Segurança Alimentar), em 1993.

Se na Assistência Social, a qual também contava com capacidades estatais frágeis previamente ao período de redemocratização, a realização da $1^{\text {a }}$ Conferência e a criação do conselho nacional no início da década de 1990 integraram um processo amplo de reforma setorial, na Segurança Alimentar é mais apropriado dizer que o papel desempenhado pelo Consea, no momento de sua criação, foi o de colaborar para a fundação propriamente dita dessa política no país. Esse conselho foi um desdobramento da Ação da Cidadania Contra a Fome, a Miséria e pela Vida, que surgiu, por sua vez, a partir do Movimento pela Ética na Política (MEP), construído em torno da campanha pró-impeachment de Fernando Collor ${ }^{13}$. A partir do momento em que passou a incorporar à sua pauta demandas por emprego, a Campanha colocaria no debate as questões e as condições mais estruturais vinculadas ao problema da fome e da pobreza, demandando, assim, de forma mais acentuada, articulações com as agências estatais (ALMEIDA, 2006). O Consea decorre desse processo e marca a criação de estruturas institucionais governamentais explicitamente comprometidas com uma política de segurança alimentar, ainda que o tema do provimento à alimentação já contasse com lastro no Estado. Esse conselho agiu como órgão máximo na operação de um Plano de Combate à

12 A Segurança Alimentar não entrou como um capítulo específico na Constituição de 1988.

13 Importante considerar que a força adquirida por essa iniciativa se deveu também, como informam Moura e Nicoletti (2016), à criação da Companhia Nacional de Abastecimento (Conab) e à divulgação, pelo Ibase e IBGE, no início da década de 1990, de um estudo intitulado Mapa da Fome, que apontava a fome como um grave problema no país. 
Fome e à Miséria, e como organizador, em 1994, da I Conferência Nacional de Segurança Alimentar.

No decorrer da década de 1990, sob o governo FHC, notamos estagnação e retrocesso nesse processo de incremento de capacidades estatais nacionais nas duas áreas aqui tratadas. Como instâncias isoladas na estrutura governamental, sem suporte de outras capacidades estatais técnico-administrativas voltadas à mesma área, sem contar com o apoio e estímulo do governo federal, o CNDM permaneceu pouco ativo e o Consea foi extinto em 1995. A institucionalização dessas políticas continuou a ocorrer, porém, por meio de um ritmo bastante desigual e descontínuo no território brasileiro, a partir de experiências municipais, estaduais e da mobilização da sociedade civil, principalmente em capitais e nos municípios maiores. Por exemplo, ao longo dos anos de 1990, o agravamento do problema da fome continuou fomentando um engajamento militante e uma reivindicação de ação institucional no âmbito da segurança alimentar que resultou, no final dos anos 1990, na criação do Fórum Brasileiro de Segurança Alimentar e Nutricional. No caso das Políticas para Mulheres, o período foi marcado, além de experiências governamentais locais, por parcerias entre agências de fomentos, ONGs e poder público para implementação de programas específicos voltados às mulheres.

Esse processo desigual e descontínuo de institucionalização legou, entretanto, um saldo importante, não apenas porque ele foi marcado pelo incremento de capacidades estatais nos subníveis governamentais (com a criação de programas, órgãos especializados e conselhos), mas, também, porque na sua esteira, os atores societais engajados na institucionalização de demandas foram adquirindo uma configuração de comunidades de políticas setoriais, acumulando saberes e recursos organizacionais para uma atuação junto ao Estado. Nessa condição, puderam aproveitar as oportunidades políticas abertas na década de 2000, com a chegada do PT à Presidência da República, momento em que ativistas oriundos de vários movimentos sociais passaram a ocupar posições de comando no governo, colaborando com o processo de institucionalização de demandas. 
Nas duas áreas, o período marcou a criação de órgãos governamentais na esfera nacional, a reforma ou a reativação dos conselhos nacionais, a inclusão das temáticas como prioridades nos PPAs (Planos Plurianuais) e a realização de conferências nacionais. A partir da chegada do PT ao governo federal, desencadeia-se, assim, uma "segunda onda de institucionalização", que tem "efeito cascata" nos subníveis federativos (ALMEIDA; BELANÇON; CHAVES, 2019).

Em 2003, o Consea é recriado, impulsionando, como no caso das mulheres, a criação de instâncias da mesma natureza nos subníveis federativos. Em 2004, é realizada a II ${ }^{a}$ Conferência Nacional de SAN (Segurança Alimentar e Nutricional), da qual decorre a proposição de uma Lei Orgânica de SAN e, em 2006, foi sancionada a Lei Nacional de Segurança Alimentar e Nutricional, que criou o Sistema Nacional de Segurança Alimentar (MOURA; NICOLETTI, 2016). Essa segunda conferência foi seguida de mais três, até 2015, e elas tiveram papel importante de "agendamento", fortalecendo o tema na agenda governamental (SOUZA, 2013).

No caso das mulheres, em 2003 foi criada a Secretaria Especial de Políticas para Mulheres (SPM) e, em 2004, realizada a primeira Conferência, a que se seguiram mais quatro, até 2016. As conferências nacionais tiveram um papel fundamental, resultando em planos que estabeleciam diretrizes para os subníveis federativos agirem nessa área de política pública (ALMEIDA; BELANÇON; CHAVES, 2019). Os planos também estabeleciam incentivos de repasse de recursos para os municípios e estados estruturarem as políticas para mulheres nos seus contextos, como a criação de estruturas governamentais para o setor.

Assim, nesse período, a atuação combinada de Conferências e Conselho Nacional, bem como o seu resultado na formulação de planos nacionais, agiu de maneira importante no incremento de capacidades estatais técnico-administrativas e político-relacionais e na articulação das comunidades de políticas nas duas áreas, com efeito "cascata" para os subníveis governamentais. Esse processo de estruturação de políticas nascentes corre risco de interrupção com a mudança de contexto político, delineado desde o fim do segundo 
mandato de Dilma Rousseff e aprofundado com a ascensão das forças conservadoras ao governo federal nas eleições de 2018. Nessa direção, é exemplar a investida do novo governo, no seu primeiro momento, contra o Consea (cf. nota de rodapé 1).

\section{Cultura e Meio Ambiente: papel episódico ou contingencial}

A área da Cultura ocupa posição intermediária no gráfico apresentado, tanto em relação à arquitetura participativa quanto à estrutura institucional. Já o Meio Ambiente divide essa mesma região com a Cultura em relação às IPs, mas se posiciona à frente quanto à estrutura institucional, estando atrás somente da Saúde nesse quesito. Isso sugere que a área da Cultura possui força mediana tanto em termos de IAP quanto de IEI, ao passo que Meio Ambiente possui força mediana no IAP e relativamente maior força quanto ao IEI. No entanto, as duas áreas são analisadas em conjunto porque suas IPs desempenharam papel episódico ou contingencial no processo de institucionalização das suas respectivas políticas, ou seja, tiveram importância em momentos pontuais, sendo neutralizadas em outros.

Isso está relacionado à existência ou não de capacidades estatais prévias - em sua dimensão técnico-administrativa - e ao fato de que as oportunidades políticas para a implementação de políticas participativas nesses setores só ocorreram mais recentemente, a partir dos anos 2000. Não obstante, as diferentes configurações das comunidades das políticas setoriais conferiram caracterização distinta a esse papel episódico. No caso da Cultura, a adoção das IPs e o dinamismo dos agentes e atores políticos do setor encetaram um processo acelerador de reivindicações e conquistas de estrutura institucionais técnico-administrativas até então incipientes. Já o Meio Ambiente, desde longa data, possuía estruturas mais robustas antes do advento das IPs, e a sua comunidade de política encontrava-se mobilizada em outros espaços, como os fóruns internacionais. Assim, no processo de institucionalização de demandas da área, as IPs tiveram um papel contingencial e coadjuvante, por assim dizer. Vejamos com mais detalhes. 
Até a realização da I Conferência Nacional (2005), a Cultura contava apenas com Ministério (MinC), instituído desde 1985, e o Conselho Federal, criado desde a década de 1930, mas como braço do Estado, sem abertura para participação da sociedade civil nos termos da Constituição de 1988. Essas duas instituições mantiveram-se marginais à operacionalização da política. Entre os poucos avanços da área, estava a chamada Lei Rouanet, de 1991, que, apesar de criar incentivos financeiros para a área, não os institucionalizou. Os poucos conselhos municipais existentes até o início da década de 2000 vivenciavam certo "cansaço", dada a dificuldade de apoio institucional às suas demandas (FARIA; MOREIRA; VERSOLATO, 2005, p. 6), inclusive com questionamentos sobre sua posição na estrutura de governo local e seu papel na política. Havia pouca ou nenhuma articulação com o Conselho Nacional e pouco diálogo com o Ministério. Pode-se dizer que, até o momento da realização da I Conferência, se comparado com áreas como a da Saúde ou do Meio Ambiente, as capacidades técnico-administrativas eram bastante incipientes, apesar das duas décadas de existência do Ministério naquela altura. Não havia, por exemplo, fundos, planos ou sistema da política.

Com a janela de oportunidades criada a partir da chegada do ministro Gilberto Gil (2003-2008) ao MinC, mostrando-se aberto ao diálogo com diversos setores da sociedade, conferências foram convocadas e canais de participação implantados para subsidiar a estruturação da área. Com efeito, nas primeiras duas Conferências Nacionais, o Plano Nacional e o Sistema de Cultura foram reivindicados pelos presentes, como revelam seus documentos (MARTELLI, TONELLA; COELHO, 2021).

Válido dizer que tanto o Plano quanto o Sistema Nacional foram aprovados (Lei n. 12.343/2010) no momento imediatamente posterior às duas primeiras conferências, embora ainda permaneçam passíveis de regulamentação. Também o conselho nacional do setor foi revitalizado no entremeio das conferências, em 2007, passando a se chamar Conselho Nacional de Política Cultural (CNPC). Explica Vidigal (2010, s. p.): “a diferença básica deste conselho em relação 
ao Conselho Nacional de Cultura, constituído durante a gestão FHC, é que o CNPC incorpora, de forma efetiva e pela primeira vez na história deste país, a sociedade civil". Com isso, a comunidade de política do setor ganha força e dinamismo. Os membros do conselho foram escolhidos durante a conferência nacional. Desse modo, em relação ao que existia antes da entrada de Gilberto Gil no ministério, o setor começava a ganhar ossatura, sendo as IPs estratégicas nos processos de articulação de atores e planejamento de ações.

Do cansaço experimentado pelos conselhos municipais no início dos anos 2000, a área passou a ter fôlego renovado. De acordo com as Munics e Estadics, entre 2010 e 2014, foram realizadas 15 conferências estaduais e 1561 municipais. Menos de uma década após a realização da I Conferência, passaram a existir conselhos estaduais nas 27 unidades da federação e em 2152 municípios. Para se ter uma dimensão, até o ano 2000 eram menos de 300 conselhos municipais na área, concentrados na Região Sudeste (CALABRE, 2010, p. 295).

Desse trajeto, depreende-se que, em um curto espaço de tempo, criou-se uma arquitetura participativa relativamente densa e se acelerou o processo de implementação de estruturas administrativas, em um momento efervescente para o setor, durante o qual também foi criada e reestruturada uma série de programas e projetos de incentivos, como os Pontos de Cultura e o Programa Cultura Viva, entre outros.

A III Conferência, realizada em 2013, reivindicava mais fortemente a criação de um sistema de financiamento público e de um Fundo Nacional para Cultura (denominado de Procultura) ${ }^{14}$. Mas a IV Conferência, prevista para ocorrer em 2017, não chegou a ser realizada. Nesse meio tempo ocorreu a destituição da presidenta Dilma Rousseff, interrompendo o processo de institucionalização do setor. Durante a gestão Temer, o Minc chegou a ser extinto,

14 O Procultura seria uma reforma da Lei Rouanet, formado por quatro mecanismos: Fundo Nacional da Cultura, Incentivos Fiscais a Projetos Culturais, Fundo de Investimento Cultural e Artístico - Ficart e vale Cultura (RUBIM, FERNANDES; RUBIM, 2010). 
depois recriado pela pressão exercida tanto por parte dos atores políticos do setor quanto da sociedade em geral. Com a eleição de Bolsonaro, o Minc foi rebaixado à Secretaria de Cultura e incorporado ao Ministério da Cidadania, que absorveu, também, as áreas dos Esportes e do Desenvolvimento Social.

Nesse sentido, na Cultura, as IPs não assumiram um papel fundante da política (como no caso da Política das Mulheres e Segurança Alimentar), mas tiveram o papel de acelerar sua construção. E isso foi possível graças à oportunidade política, aberta no governo federal após a chegada do PT, e apropriada pela ativa comunidade setorial que direcionou os esforços às IPs.

Processo diverso se verifica com o Meio Ambiente. Desde a década de 1980, a área conta com estrutura institucional robusta, com Ministério (MMA), Sistema Nacional, Plano Nacional e Fundo Nacional. Embora o setor tenha constituído Conselho Nacional desde aquela década, sua primeira conferência nacional veio a ser realizada somente em 2003. E o pico da onda de criação dos seus conselhos municipais se deu somente na segunda metade da década de 2000 (COELHO et al., 2019), especialmente no Ministério de Marina Silva (2003-2008).

Esse ingresso tardio da agenda ambiental nas IPs pode estar associado à valorização de outros espaços e processos participativos por parte da comunidade de políticas da área. Por mais paradoxal que possa parecer, a agenda ambiental é global e internacional, tanto quanto é local e territorial. Desde a década de 1970, a agenda ambiental ganhou contornos internacionais, por exemplo, em 1972, a ONU organizou a primeira conferência mundial sobre o meio ambiente, realizada em Estocolmo, na Suécia. Desde então, diversos outros fóruns de grandes dimensões foram realizados, como o Protocolo de Montreal (1987), a ECO-92 (1992), o Protocolo de Kyoto (1997), a Rio+10 (2002), a Rio+20 (2012) e o Acordo de Paris (2015). No contexto desses eventos, atores internacionais, como ONGs e organizações ambientalistas, pautaram o debate sobre a participação da sociedade na política ambiental. Inclui-se nesses espaços internacionais parte da comunidade de política desse setor 
no Brasil. Por outro lado, outra parte do "movimento ambientalista" no país, que teve a sua gênese nos estratos da classe média, mobilizou-se a partir de "contexto de micromobilização", isto é, "microcontextos de interação social, tais como instituições profissionais, grupos culturais e redes de amizade, nos quais cidadãos comuns se convertem em ativistas ambientalistas" (ALONSO; COSTA; MACIEL, 2007, p. 154).

Acrescenta-se o fato de não se verificar, no Meio Ambiente, uma comunidade de política orientada por objetivos e pautas comuns, pois como acima mencionado, a temática do meio ambiente incitou o encontro de diversos atores oriundos de distintos espaços sociais, inclusive internacional, como empresários, sindicalistas, ambientalistas, financistas, igrejas, disputando o próprio sentido do que se entende por "ambientalização". Essa heterogeneidade tem levado mais a uma disputa de agenda entre os membros da comunidade do que à construção de pautas e propostas consensuais (MARTELLI et al., 2018, p. 255), o que também se reflete na diversidade de espaços de atuação, legando às IPs uma atuação bastante fragmentada e ocasional. Evidência disso é que os conselhos municipais de Meio Ambiente foram menos mobilizados do que em outras áreas, o que indica que a sua comunidade investiu menos energia nesses fóruns. Analisando o número médio de reuniões anuais realizadas por conselhos em 10 áreas de políticas públicas, Coelho e colaboradores (2019) observaram que o Meio Ambiente fica em penúltimo lugar, com apenas 4,4 reuniões anuais realizadas na média ${ }^{15}$.

Assim, a arquitetura participativa do setor veio a se estruturar somente de forma tardia e não esteve no centro da institucionalização da política, isto é, foi secundária na institucionalização das estruturas técnico-administrativas, uma vez que essas já se encontravam presentes previamente. Isso não quer dizer, todavia, que as IPs não tiveram a sua importância. Na gestão de Marina

15 Segundo esses dados, os números médios de reuniões anuais são, na ordem, os seguintes: Saúde $(11,2)$; Assistência Social (10,2); Criança e Adolescente (8,6); Educação (7,6); Direitos Humanos (7,6); Igualdade Racial (6,3); Direitos da Pessoa com Deficiência (6,2); Direitos do Idoso (5,9); Mulheres (5,2); Direitos da Juventude (5,1); Direitos LGBTT (4,9); Segurança Pública (4,8); e Segurança Alimentar (3,8). 
Silva, o funcionamento do Conselho Nacional de Meio Ambiente foi intenso e constante, integrando diferentes setores para trabalhar os diversos interesses envolvidos em questões ambientais. As conferências de Meio Ambiente tiveram papel de destaque na articulação de vários atores, na tentativa de ampliar o escopo dos que participam do setor. Na Conferência de 2005, por exemplo, estava claro o objetivo de promover maior envolvimento de diferentes ministérios, governos estaduais e municipais, sociedade civil, incluindo o setor privado, as ONGs, os povos indígenas, os quilombolas e as comunidades tradicionais, com ênfase em uma ótica compartilhada e participativa, defendida pela então ministra Marina Silva (ABERS; OLIVEIRA, 2015).

Mas, o fato é que, diferentemente da área da Cultura, por exemplo, as IPs ganharam tração na área do Meio Ambiente em um momento em que ela já estava bastante estruturada. Daí o seu caráter episódico ou contigencial na institucionalização do setor.

\section{Oportunidades políticas, comunidades de políticas e capacidades estatais pré-existentes: notas conclusivas sobre o papel das IPs nas políticas públicas}

Neste artigo, buscamos qualificar o papel das IPs na trajetória e na estruturação de suas respectivas áreas de políticas com base em uma abordagem analítica relacional entre estrutura participativa e estrutura institucional, ou entre as capacidades político-relacionais e as técnico-administrativas. Defendemos a ideia de que uma compreensão mais adequada do papel exercido pelas IPs no sistema de direitos no Brasil exige uma avaliação que não adote restritamente os critérios contidos no "percurso modelo" de institucionalização. Com isso, o nosso radar se amplia e pode captar melhor a variação de papel exercido pelas IPs nas suas respectivas políticas, além de nos armar melhor para a avaliação de seu futuro em contextos adversos.

Ao recuperar marcos dos processos que levaram a mudanças institucionais e ao incremento nas capacidades estatais nas seis áreas aqui consideradas, argumentamos que as IPs foram centrais no 
projeto reformador setorial da Saúde e Assistência Social, desempenhando, nessas áreas, um papel reformador; em contraste, nas áreas de Política para Mulheres e Segurança Alimentar, as IPs colaboraram de maneira importante nos processos implicados com sua própria criação e reconhecimento, exercendo nelas, portanto, um papel fundante; as IPs tiveram um papel episódico na trajetória das políticas de Cultura e Meio Ambiente, colaborando para acelerar mudanças institucionais na primeira e permanecendo como coadjuvante na trajetória da segunda.

Os casos aqui analisados nos permitem sugerir que essa variação de papéis pode ser explicada pela ação combinada de três fatores: (i) oportunidades políticas; (ii) dinamismo e configuração das comunidades de políticas; (iii) capacidades estatais pré-existentes nas políticas. A forma específica como esses fatores interagiram em cada área de política pública resultou naquela variação.

O contexto mais amplo das lutas pela democratização do país abriu oportunidades políticas para a mobilização de atores interessados em mudanças nas políticas públicas. A associação entre “participação e políticas públicas” expressou-se em uma ideia-força para um conjunto variado de atores que estavam interessados na ampliação do acesso aos direitos e à democratização dos processos decisórios. As IPs cristalizaram, em larga medida, as apostas contidas naquela ideia-força e foram percebidas por um conjunto de atores como estratégicas para a implementação ou o impulso de mudanças institucionais, tendo em vista a histórica baixa permeabilidade do sistema político brasileiro à circulação de elites.

Mas o papel que as IPs desempenharam nas políticas desde então, sob as restrições ou sob as novas oportunidades encontras nas décadas de 1990 e 2000, dependeu também do grau de capacidades estatais mais ou menos estruturadas previamente. Esse fator importa porque delineia o escopo e conteúdo do desafio que está em jogo para atores interessados em mudanças institucionais e impacta o ritmo de sua implementação, dado que delimita apoios ou resistências na burocracia estatal. $\mathrm{O}$ desafio dos atores pode ser desde a implementação de reformas - seja de qualquer extensão -, 
levando-se em conta, em alguma medida, estruturas institucionais já constituídas ou, em contraste, a própria luta pelo reconhecimento de que um determinado "problema" deve ser alvo do engajamento estatal. Assim, no caso da Saúde, as IPs se constituíram centrais para o projeto reformador, enquanto para a Segurança Alimentar o desafio estava no "agendamento" de um problema no governo, para o que as IPs parecem ter cumprido um papel importante.

Por outro lado, a configuração e a dinâmica de uma determinada comunidade de política são também relevantes porque explicam as diferentes condições em que se encontram os atores para aproveitar conjunturas em favor de suas propostas de mudanças. Por exemplo, enquanto na área da mulher a sua comunidade de política estava em processo de construção na década de 1980, na Saúde esse período foi marcado pelo fortalecimento e pluralização de sua comunidade. Além disso, as IPs ocupam distintos lugares nas estratégias de atores interessados em mudanças, podendo ser vistas pelas redes ativistas como mais ou menos centrais, dependendo da política pública em questão. Por exemplo, no Meio Ambiente, os atores estão mobilizados em redes e instâncias globais e sua comunidade de política, marcadamente heterogênea, parece não ter enxergado as IPs como estratégicas para a defesa de projetos para a área. Distintamente, na Assistência Social, o forte compromisso existente com a participação, legado da própria atuação de profissionais dessa área na construção do SUS, e a necessidade de pluralizar a comunidade de políticas, diminuindo o peso das organizações filantrópicas, colocou os conselhos e as conferências no centro de um projeto de mudança para a área.

O objetivo deste artigo foi, portanto, mostrar a singularidade de atuação das IPs na trajetória de institucionalização das seis áreas aqui analisadas, a depender da forma como interagiram os três fatores - oportunidades políticas, dinamismo das comunidades de política e prévias capacidades técnico-administrativas. Da observação das diferentes performances, chegamos à tipologia proposta. O desafio, agora, é observar como as IPs, em cada área de política, responderão ao contexto de desmonte da participação social que 
se fortalece desde o final do último governo de Dilma Roussef, bem como compreender os fatores que importam para moldar sua atuação nesse cenário. Trata-se de uma empreitada que pede outro esforço de pesquisa.

\section{Referências}

ABERS, Rebecca Neaera; OLIVEIRA, Marília Silva de. Nomeações políticas no Ministério do Meio Ambiente (2003-2013): interconexões entre ONGs, partidos e governos. Opinião Pública, Campinas, v. 21, n. 2, p. 337-364, ago. 2015.

ALMEIDA, Carla. O marco discursivo da participação solidária e a redefinição da questão social no Brasil. 2006. Dissertação (Mestrado em Ciência Política) - Instituto de Filosofia, Letras e Ciências Humanas, Universidade Estadual de Campinas, Campinas, 2006.

ALMEIDA, Carla; BELANÇON, Milena; CHAVES, Karen Laís Barbero. A institucionalização de demandas feministas no Brasil: uma análise dos Organismos, Conselhos e Serviços Especializados para Mulheres nos municípios. Mediações, Londrina, v. 24, n. 3, p. 184-199, 2019.

ALMEIDA, Débora Rezende de. Resiliência institucional: para onde vai a participação nos Conselhos Nacionais de Saúde e dos Direitos da Mulher? Caderno CRH, Salvador, v. 33, p. 1-24, 2020.

ALONSO, Angela; COSTA, Valeriano; MACIEL, Débora. Identidade e estratégia na formação do movimento ambientalista brasileiro. Novos Estudos CEBRAP, São Paulo, n. 79, p. 151-167, 2007. BARBOSA, Gisele Heloise; KERBAUY, Maria Teresa Miceli. Instituição participativa e institucionalização da participação: uma discussão conceitual. In: ENCONTRO INTERNACIONAL PARTICIPAÇÃO, DEMOCRACIA E POLÍTICAS PÚBLICAS, 2., 27-30 abr. 2015, Campinas. Anais [...]. Campinas: UNICAMP, 2015. p. 1-25. 
BORBA, Julian. Participação política como resultado das instituições participativas: oportunidades políticas e o perfil da participação. In: PIRES, Roberto Rocha C. (org.). Efetividade das instituições participativas no Brasil: estratégias de avaliação. Brasília: Ipea, 2011. p. 65-76.

CALABRE, Lia. Políticas culturais no Brasil: história e contemporaneidade. Fortaleza: Banco do Nordeste do Brasil, 2010.

COELHO, Rony; ALMEIDA, Carla; MARTELLI, Carla Giani; LUCHMANN, Ligia. A participação conselhista no Brasil: uma proposta de análise por meio do Índice de Potencial Participativo dos Conselhos nos municípios (IPPC). In: ENCONTRO INTERNACIONAL PARTICIPAÇÃO, DEMOCRACIA E POLÍtICAS PÚBLICAS, 4., Porto Alegre, 2019. Anais [...]. Porto Alegre: PDPP/UFRGS, 2019. p. 1-22.

CÔRTES, Soraya Vargas. Construindo a possibilidade da participação dos usuários: conselhos e conferências no Sistema Único de Saúde. Sociologias, Porto Alegre, ano 4, n. 7, p. 18-49, jan./jun. 2002.

CÔRTES, Soraya Vargas. Instituições participativas e acesso a serviços públicos nos municípios brasileiros. In: PIRES, Roberto Rocha C. (org.). Efetividade das instituições participativas no Brasil: estratégias de avaliação. Brasília: Ipea, 2011. p. 77-84.

CÔRTES, Soraya Vargas. Policy community defensora de direitos e a transformação do Conselho Nacional de Assistência Social. Sociologias, Porto Alegre, ano 17, n. 38, p. 122-154, jan./abr. 2015.

COSTA, Ana Maria. Participação social na conquista das políticas de saúde para mulheres no Brasil. Ciência e Saúde Coletiva, Rio de Janeiro, v. 14, n. 4, p. 1073-1083, jul./ago. 2009.

DOWBOR, Monika. A arte da institucionalização: estratégias de mobilização dos sanitaristas (1974-2006). 2012. Tese (Doutorado em Ciência Política) - Departamento de Ciência Política da Faculdade de Filosofia, Letras e Ciências Humanas, Universidade de São Paulo, São Paulo, 2012. 
FARIA, Hamilton; MOREIRA, Altair; VERSOLATO, Fernanda (org.). Você quer um bom conselho?: conselhos municipais de cultura e cidadania cultural. São Paulo: Instituto Pólis, 2005.

FREITAS, Rita; BARROS, Nivia; MESQUISTA, Adriana; SILVA, Iris da. História do serviço social: resgatando uma história de mulheres. Em Pauta, Rio de Janeiro, n. 42, v. 16, p. 228-246, 2018.

GOMIDE, Alexandre; PEREIRA, Ana Karine; MACHADO, Raphael. Apresentação: o conceito de capacidade estatal e a pesquisa científica. Sociedade e Cultura, Goiânia, v. 20, n. 1, p. 3-12, jan./jun. 2017.

GURZA LAVALLE, Adrian. Após a participação: uma nota introdutória. Lua Nova, São Paulo, v. 84, p. 13-23, 2011.

GURZA LAVALlE, Adrian; BARONE, Leonardo Sangali. Conselhos, associações e desigualdade. In: ARRETCHE, Marta (org.). Trajetórias das desigualdades: quanto o Brasil mudou nos últimos cinquenta anos. São Paulo: Editora Unesp, 2015. p. 51-76.

GURZA LAVALLE, Adrian; CARLOS, Euzeneia; DOWBOR, Monika; SZWAKO, José. Movimentos sociais, institucionalização e domínios de agência. In. GURZA LAVALLE, Adrian et al. (org.). Movimentos sociais e institucionalização: políticas sociais, raça e gênero no Brasil pós-transição. Rio de Janeiro: EdUERJ, 2019. p. 21-86.

GURZA LAVALLE, Adrian; VOIGT, Jessica; SERAFIM, Liza. O que fazem os conselhos e quando o fazem? Padrões decisórios e o debate dos efeitos das instituições participativas. DADOS - Revista de Ciências Sociais, Rio de Janeiro, v. 59, n. 3, p. 609-650, 2016.

HALL, Peter A.; TAYLOR, Rosemary. As três versões do neo-institucionalismo. Lua Nova, São Paulo, n. 58, p. 193-223, 2003.

ISUNZA VERA, Ernesto; GURZA LAVALLE, Adrian. Arquitetura da participação e controles democráticos no Brasil e no México. Novos Estudos CEBRAP, São Paulo, n. 92, p. 105-121, 2012. 
LAWRENCE, Thomas B.; WINN, Monika; JENNINGS, Devereaux. The temporal dynamics of institutionalization. The Academy of Management Review, [Online], v. 26, n. 4, p. 624-644, Oct. 2001.

MARTELlI, Carla Giani; TONELLA, Celene; COELHO, Rony. Estrutura institucional e arquitetura participativa em setores de políticas públicas. Revista Política \& Sociedade, Florianopólis, 2021. Artigo no prelo.

MARTELLI, Carla Giani; TONELLA, Celene; JARDIM, Maria Chaves; ROMÃO, Wagner. Conferências nacionais e políticas públicas: uma análise longitudinal nas áreas de assistência social, meio ambiente e políticas para as mulheres. In: MARTELLI, Carla; JARDIM, Maria; GIMENES, Éder. (org.). Participação política e democracia no Brasil contemporâneo. São Paulo: Cultura Acadêmica, 2018. p. 235-274.

MAYKA, Lindsay. Building participatory institutions in Latin America. Cambridge: University Press, 2019.

MENICUCCI, Telma. Política de saúde no Brasil: continuidades e inovações. In: ARRETCHE, Marta; MARQUES, Eduardo; FARIA, Carlos (org.). As políticas da política: desigualdades e inclusão nos governos do PSDB e do PT. São Paulo: Editora Unesp, 2019.

MOURA, Joana Tereza Vaz; NICOLETTI, Milenna. O trânsito das questões da agenda pública para a governamental: a institucionalização da segurança alimentar nas políticas públicas. Baru, Goiânia, v. 2, n. 2, p. 176-189, jul./dez. 2016.

PIRES, Roberto; GOMIDE, Alexandre. Governança e capacidades estatais: uma análise comparativa de programas federais. Revista de Sociologia e Política, Curitiba, v. 24, n. 58, p. 121-143, 2016. SCHUMAHER, Maria Aparecida; VARGAS, Elizabeth. Lugar no governo: álibi ou conquista? Estudos Feministas, Florianópolis, v. 1, n. 2, p. 348-64, 1993. 
SILVA, Sandro Pereira. A trajetória histórica da segurança alimentar e nutricional na agenda política nacional: projetos, descontinuidades e consolidação. Rio de Janeiro: Ipea, 2014. (Texto para Discussão n. 1953).

RUBIM, Antonio Albino Canelas; FERNANDES, Taiane; RUBIM, Iuri. Políticas culturais, democracia e conselhos de cultura. Salvador: EDUFBA, 2010.

SOUZA, Clóvis Henrique Leite de. A que vieram as conferências nacionais? Uma análise dos objetivos dos processos realizados entre 2003 e 2010. In: AVRITZER, Leonardo; SOUZA, Clóvis (org.). Conferências nacionais, atores, dinâmicas participativas e efetividade. Brasília: Ipea, 2013. p. 53-72.

SOUZA, Clóvis Henrique Leite de. Capacidades estatais para a promoção de processos participativos: atributos do aparato burocrático ou condições temporárias para a ação? Sociedade e Cultura, Goiânia, v. 20, n. 1, p. 105-126, 2017.

TARROW, Sidney. O poder em movimento: movimentos sociais e confronto político. Rio de Janeiro: Vozes, 2009.

TEIXEIRA, Ana Cláudia Chaves; SOUZA, Clóvis Henrique Leite de; LIMA, Paula. Arquitetura da participação no Brasil: uma leitura das representações políticas em espaços participativos nacionais. Brasília: Ipea, 2012. (Texto para Discussão 1735).

VIDIGAL, Gustavo. O sentido da mudança. In: RUBIM, Antonio; FERNANDES, Taiane; RUBIM, Iuri. Políticas culturais, democracia e conselhos de cultura. Salvador: EDUFABA, 2010.

\section{Resumo}

A partir de uma abordagem que enfatiza a mútua constituição entre capacidades político-relacionais e técnico-administrativas, o objetivo deste artigo é qualificar o papel que as Instituições Participativas (IPs) assumiram na estruturação e na trajetória das políticas públicas no Brasil. Com base em seis áreas de políticas, sugerimos a seguinte tipologia para compreender a variação que as IPs tiveram na institucionalização das políticas: papel reformador, fundante ou episódico/contingencial. Argumentamos que a ação combinada de três fatores - capacidades técnico-administrativas 
pré-existentes, oportunidades políticas e dinamismo e configuração das comunidades de políticas - ajuda a compreender a variação.

Palavras-chave: Instituições participativas. Políticas públicas. Institucionalização. Capacidades estatais.

\section{Abstract}

Based on an approach that emphasizes the mutual constitution between political-relational and technical-administrative capacities, this article explores the roles of Participatory Institutions (PIs) in the policy construction and change in Brazil. Based on six policy areas, we propose the following typology of roles to understand variation in the effect of PI on policy institutionalization: reform, foundation or episodic/contingent roles. We argue that the combined action of three factors - pre-existing technical and administrative capacities, political opportunities and of the characteristics of policy communities - helps to understand the variation. Keywords: Participatory institutions. Public policies. Institutionalization. State capacities.

Recebido em 02 de outubro de 2020 Aprovado em 23 de março de 2021 